\title{
Study on asphalt pavement pothole structure based on finite element
}

$$
\text { Zhou Weiqi }{ }^{1, a} \text {, LI Xinhe }{ }^{2, \mathrm{~b}} \text {, Wang Kun }{ }^{3, \mathrm{c}}
$$

${ }^{1}$ Jiangsu Province Suzhou city Wujiang District Highway Management Department, Suzhou, 215100, China

2 Jiangsu Provincial Communication Planning and Design Institute Co, Ltd, Nanjing, 210005, China

${ }^{3}$ Jiangsu Provincial Communication Planning and Design Institute Co, Ltd, Nanjing, 210005, China

aemail: 574388998@qq.com, bemail: lixinhe8719@163.com, ${ }^{\mathrm{C}}$ email: wangkun1024@163.com

Keywords: pothole; law of development; finite element method; combination of pavement structural; Moving load

\begin{abstract}
With the help of ABAQUS and its subroutine DLOAD calculated the asphalt pavement response of different pothole area and combination of pavement structural from moving load. So as to arrive the law of development to pothole and the best combination of pavement structure to resist the pothole .Results show that the inflection point in the development of pothole is $53.25 \mathrm{~cm} \times 53.25 \mathrm{~cm}$ of pothole area; The best combination of pavement structure to resist the pothole is $4.5 \mathrm{~cm}+6 \mathrm{~cm}+9.5 \mathrm{~cm}$. The results could use to define the best time to repair pothole, and provide the best combination of pavement structural to resist pothole.
\end{abstract}

\section{Introduction}

Potholes is common disease of asphalt pavement, which cause serious security hidden danger if not timely repair. But when to repair the potholes is obscure, and what combination of pavement structure to boycott Potholes disease [1]. While the case of load or pavement structure was relatively complex, the numerical solution of the finite element method was needed to consider [2]. In this paper, the finite element software ABAQUS was used to establish contact model that was closer to actual state. Then stress under moving loads on the pavement with potholes was analyzed. That provided theoretical guidance for asphalt pavement to repair potholes.

\section{Established model of asphalt pavement with potholes}

The model was established by ABAQUS: The size was 3m high (Y), 6m length (Z), 6m width $(\mathrm{X})$, the value of potholes area was $21.32 \mathrm{~cm} 2-1002 \mathrm{~cm}^{2}$, the upper layer thickness was taken as potholes depth [3]. The constraint of model underside was $\mathrm{U} 1=\mathrm{U} 2=\mathrm{UR} 3=0$, the both sides of sideway was $\mathrm{U} 1=\mathrm{UR} 2=\mathrm{UR} 3=0$, other surface was without any constraints. C3D8R solid elements was used, and mesh for the surface layer was fine; base was slightly rough, the loaded area and potholes area was encrypted grid. As shown in Figure 1.

Dual rectangular instead of the Dual circular loading surface in order to divide grid and apply moving loads. Loading surface of $16.667 \times 21.3 \mathrm{~cm}$ was determined [4], the space of two loading surfaces was $31.95 \mathrm{~cm}$. Vertical load was $0.7 \mathrm{MPa}$. In this paper, DLOAD user subroutine was written in FORTRAN to achieve load move with the change of time and space. The vehicle speed was taken as $20 \mathrm{~m} / \mathrm{s}[4]$. 


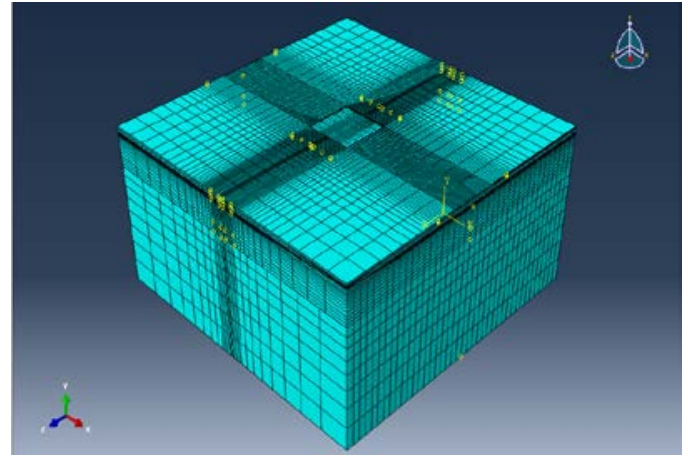

Fig 1 Meshing map of the model

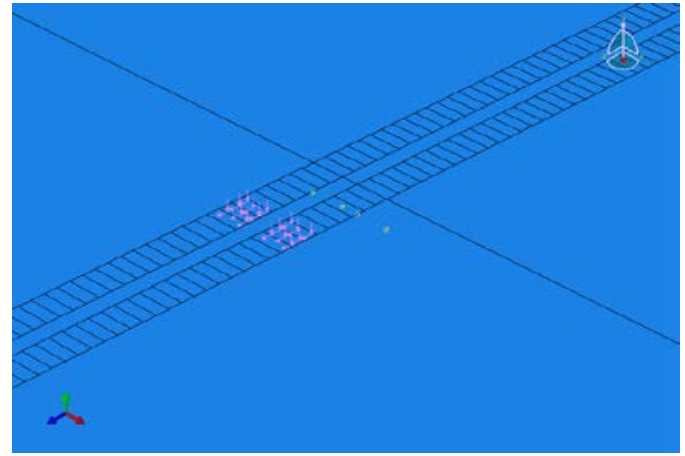

Fig 2 The distribution of load pattern

Penalty function formula of ABAQUS/Explicit was used to simulate interlayer contact. We assumed that both of contact surfaces were not separated when normal behavior of contact surface was simulated. And friction coefficient $\mu$ was used to simulate the interaction between the contact surfaces of tangential behavior [5]. Friction coefficient between asphalt layer and base was 0.399 0.829 [6]. In the paper, Friction coefficient 0.5 was used to establish contact model that was closer with the actual state of pavement structure.

\section{Determined material parameters and analysis indicators}

This article relied on the representative semi-rigid pavement structure, material parameters elastic, density and damping values as shown in Table 1.

Table 1 Material parameters of asphalt pavement

\begin{tabular}{ccccccc}
\hline Layers & materials & Thickness & $\begin{array}{c}\text { elastic } \\
(\mathrm{MPa}) \\
\left(20^{\circ} \mathrm{C}\right)\end{array}$ & $\begin{array}{c}\text { density } \\
(\mathrm{kg} / \mathrm{m} 3)\end{array}$ & $\begin{array}{c}\text { damping } \\
\text { values }\end{array}$ & $\begin{array}{c}\text { Poisson's } \\
\text { ratio }\end{array}$ \\
\hline Upper layer & Fine-grained asphalt & $4 \mathrm{~cm}$ & 1400 & 2400 & 0.9 & 0.35 \\
middle layer & Medium-grained asphalt & $6 \mathrm{~cm}$ & 1200 & 2400 & 0.9 & 0.30 \\
lower layer & $\begin{array}{c}\text { Medium-grained asphalt } \\
\text { Cement Stabilized }\end{array}$ & $8 \mathrm{~cm}$ & 1000 & 2400 & 0.9 & 0.30 \\
base & aggregate & $40 \mathrm{~cm}$ & 1500 & 2300 & 0.8 & 0.25 \\
Sub base & Lime soil & $20 \mathrm{~cm}$ & 550 & 2100 & 0.4 & 0.30 \\
Soil base & & & 45 & 1800 & 0.4 & 0.40 \\
\hline
\end{tabular}

When driving a vehicle approaching or leaving potholes, patching material in pothole would endure shear stress, then both sides of the pothole was dislocated with the old pavement , and patching material was cut. So we used maximum shear stress of surface layer as a major evaluation.

\section{Law of development to potholes}

That wheel loads from far to reach pothole location, and away was taken as a role cycle. Maximum shear stress was calculated and analyzed in the cycle, the results were shown in Figure 3.

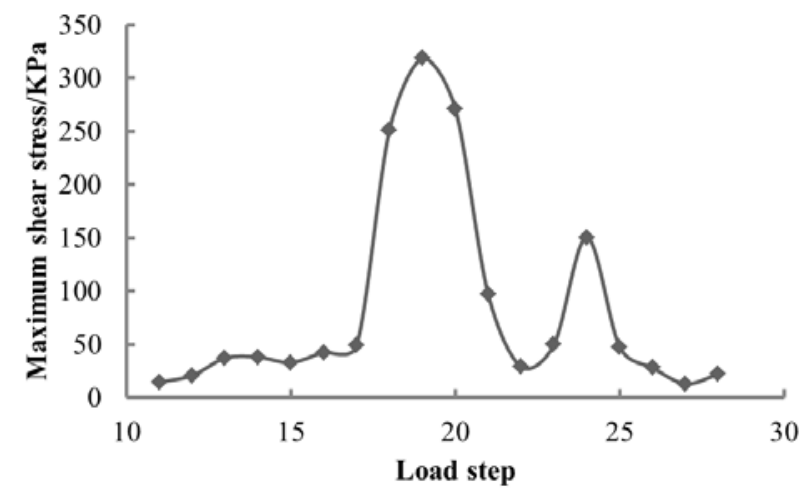

Fig 3 The maximum shear strain at the bottom of the surface layer with the load

Figure 3 shows that when the load arrived at the forefront of pothole, a peak of maximum shear stress was emerged at the bottom of the upper layer. And when the load arrived at the post of 
pothole, a peak was also emerged at the top of the upper layer. The peak at the forefront of pothole was bigger than the post. So the bottom of the upper layer at the pothole forefront was taken as the most unfavorable load position.

The maximum shear stress of the most unfavorable load position was taken as the representtative value to pothole size. Then the curve of stress with pothole size was got to simulate the development of potholes. The representative value of maximum shear stress calculated in different potholes as the Y-axis, pothole size as the $\mathrm{X}$-axis, that was shown in Figure 4.

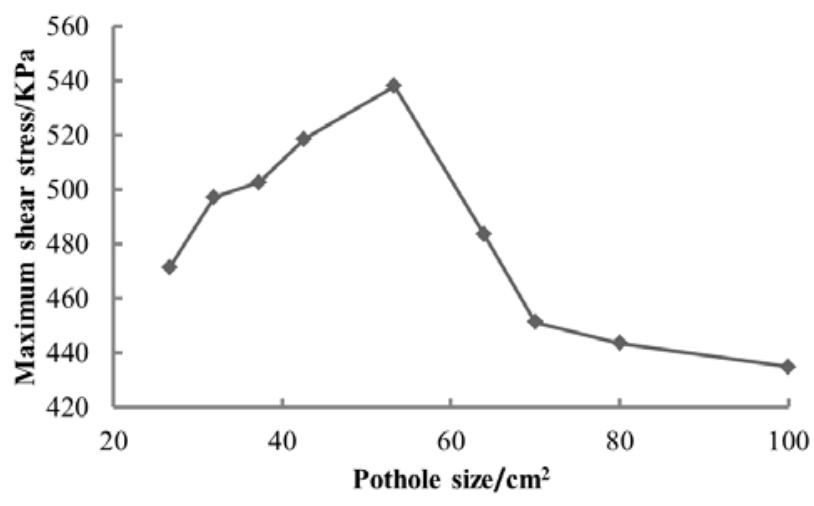

Fig 4 The maximum shear strain at the most unfavorable position with the trend of pothole

The figure shows that maximum shear stress increased linearly when the pothole size was increased by $26.63 \mathrm{~cm} \times 26.63 \mathrm{~cm}$ to $53.25 \mathrm{~cm} \times 53.25 \mathrm{~cm}$, that increased $14.18 \%$ by slope of 2.51 . But maximum shear stress decreased linearly when the pothole size was increased by $53.25 \mathrm{~cm} \times 53.25 \mathrm{~cm}$ to $70 \mathrm{~cm} \times 70 \mathrm{~cm}$, which decreased $16.12 \%$ by slope of -5.18 . So, when the pothole size is $53.25 \mathrm{~cm} \times 53.25 \mathrm{~cm}$, that is consistent with lateral width of loads surface, the maximum shear stress value was maximum. The maximum shear stress value was larger, the pothole developed faster. Thus the inflection of rapid growth for potholes was pit area $53.25 \mathrm{~cm} \times 53.25 \mathrm{~cm}$. So as to arrive the best time for road to repair potholes was the size of potholes before the inflection point.

\section{The ability of different combinations pavement to resist potholes}

In this paper, a summary of the pavement structure type to freeway have been built refer to the relevant literature. Different combinations to surface layer thickness were analyzed using the same analysis method in 3. And the maximum shear stress of the most unfavorable load position was compared to obtain a combination with the smallest representative value. That is optimal combination of surface layer structure to resist potholes. Representative value of the maximum shear stress at different combinations to surface layer thickness was shown in Table 2.

Table 2 The maximum shear strain at the different surface layer thickness composition

\begin{tabular}{ccccc||ccccc}
\hline $\begin{array}{c}\text { surface layer } \\
\text { thickness } \\
(\mathrm{cm})\end{array}$ & $\begin{array}{c}\text { Upper } \\
\text { layer }\end{array}$ & $\begin{array}{c}\text { middle } \\
\text { layer }\end{array}$ & $\begin{array}{c}\text { lower } \\
\text { layer }\end{array}$ & $\begin{array}{c}\tau_{\max } \\
(\mathrm{KPa})\end{array}$ & $\begin{array}{c}\text { surface layer } \\
\text { thickness } \\
(\mathrm{cm})\end{array}$ & $\begin{array}{c}\text { Upper } \\
\text { layer }\end{array}$ & $\begin{array}{c}\text { middle } \\
\text { layer }\end{array}$ & $\begin{array}{c}\text { lower } \\
\text { layer }\end{array}$ & $\begin{array}{c}\tau_{\max } \\
(\mathrm{KPa})\end{array}$ \\
\hline 10 & 4 & & 6 & 442.86 & 19.5 & 4.5 & 6 & 9 & 436.50 \\
12 & 3 & 4 & 5 & 439.98 & & 4 & 7 & 9 & 442.15 \\
15 & 4 & 5 & 6 & 437.68 & & 5 & 7 & 8 & 468.95 \\
16 & 4 & 6 & 6 & 432.75 & 20 & 4 & 8 & 8 & 443.55 \\
& 4 & 5 & 7 & 452.90 & & 4.5 & 6.5 & 9 & 433.25 \\
17 & 4 & 6 & 7 & 432.30 & & 4.5 & 6 & 9.5 & 430.85 \\
& 4 & 5 & 8 & 448.10 & 21 & 4 & 7 & 10 & 442.50 \\
18 & 4 & 6 & 8 & 434.62 & 22 & 5 & 7 & 10 & 471.17 \\
& 5 & 6 & 7 & 472.30 & & & & & \\
& 4 & 7 & 8 & 438.85 & & & & & \\
\hline
\end{tabular}


From the above data showed that although the total thickness of the surface layer was same, but the maximum shear stress at the most unfavorable load position was not the same at different combinations. And increasing the thickness of middle layer could significantly improve the ability of pavement to resist potholes.

Figure 5 was shown that The maximum shear strain with the trend of layer thickness. When the total thickness of the surface layer was same, the minimum value of maximum shear stress corresponding to combinations was taken as the representative value.

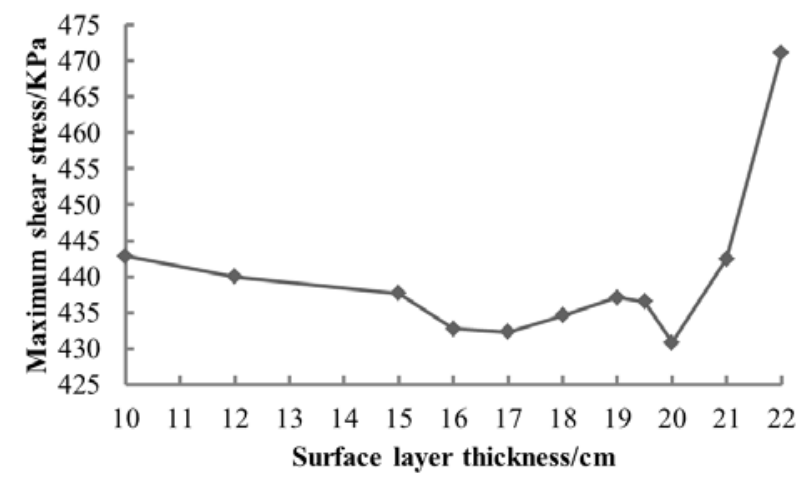

Fig 5 The maximum shear strain with the trend of layer thickness

The figure shows that maximum shear stress curve there were two bottoms corresponding to pavement surface layer thickness $17 \mathrm{~cm}$ and $20 \mathrm{~cm}$, and combination of pavement structure types were $4 \mathrm{~cm}+6 \mathrm{~cm}+7 \mathrm{~cm}$ and $4.5 \mathrm{~cm}+6 \mathrm{~cm}+9.5 \mathrm{~cm}$. The maximum shear stress corresponding to $20 \mathrm{~cm}$ was lower than $17 \mathrm{~cm}$, so the combination of pavement structure type $4.5 \mathrm{~cm}+6 \mathrm{~cm}+9.5 \mathrm{~cm}$ was the optimal combination of surface layer structure to resist potholes.

\section{Conclusion}

(1) The bottom of the upper layer at the pothole forefront was the most unfavorable load position.

(2) The best time for road to repair potholes was the size of potholes before the inflection point that was lateral width of loads surface.

(3) Although the total thickness of the surface layer was same, but the maximum shear stress at the most unfavorable load position was not the same at different combinations. And increasing the thickness of middle layer could significantly improve the ability of pavement to resist potholes.

(4) The combination of pavement structure type $4.5 \mathrm{~cm}+6 \mathrm{~cm}+9.5 \mathrm{~cm}$ was the optimal combination of surface layer structure to resist potholes, $4 \mathrm{~cm}+6 \mathrm{~cm}+7 \mathrm{~cm}$ was second.

\section{References}

[1] Al-Qadi I L, Yoo P J, Elseifi M A, et al. Creep behavior of hot-mix asphalt due to heavy vehicular tire loading[J].Journal of Engineering Mechanics, 2009, 135(11): 1265-1273.

[2] Wang Xu-cheng. Finite element method [M]:BeiJing: Tsinghua University Press, 2006.472-518.

[3] Kang Jingdong, Sun Zhuwang. Asphalt pavement cracks and pits Maintenance[D]. Xi'an: Chang'an University,2002.

[4] Liao Gong-yun, Huang Xiao-ming. ABAQUS finite element software apply in road engineering [M].NanJing: Southeast University Press,2008.153-199.

[5] Liu Hong-po. Analysis on the Mechanical Response of Semi-Rigid Base Pavement with Contact Model[D]. ChengDu: Southwest Jiaotong University,2006.

[6] Feng Ji-liang. The analysis of interlayer sliding on XinJiang oilfield highway[D].Xi'an: Xi'an Highway University,2000. 